\title{
Correction to: Criteria for the definition of Pituitary Tumor Centers of Excellence (PTCOE): A Pituitary Society Statement
}

Felipe F. Casanueva ${ }^{1} \cdot$ Ariel L. Barkan $^{2} \cdot$ Michael Buchfelder $^{3} \cdot$ Anne Klibanski $^{4} \cdot$ Edward R. Laws $^{5}$ - Jay S. Loeffler ${ }^{6}$. Shlomo Melmed ${ }^{7}$. Pietro Mortini ${ }^{8} \cdot$ John Wass $^{9} \cdot$ Andrea Giustina $^{10} \cdot$ On behalf of The Pituitary Society, Expert Group on Pituitary Tumors

Published online: 20 September 2018

(c) The Author(s) 2018

Correction to: Pituitary (2017) 20:489-498

https://doi.org/10.1007/s11102-017-0838-2

The original version of this article unfortunately contained an affiliation error in 'Collaborators for The Pituitary Society, Expert Group on Pituitary Tumors' section. Dr. Misa Pfeifer is affiliated with Medical Faculty, University of Ljubljana, Slovenia and the correct email address to contact is misa.pfeifer@gmail.com.

The original article can be found online at https://doi.org/10.1007/ s11102-017-0838-2.

Felipe F. Casanueva endocrine@usc.es

1 Division of Endocrinology, Santiago de Compostela University, Santiago de Compostela, Spain

2 Division of Endocrinology, University of Michigan Health System, Ann Arbor, MI, USA

3 Department of Neurosurgery, University Hospital Erlangen, Erlangen, Germany

4 Neuroendocrine Unit, Massachusetts General Hospital, Boston, MA, USA

5 Department of Neurosurgery, Brigham \& Women's Hospital, Boston, MA, USA
6 Department of Radiation Oncology, Massachusetts General Hospital, Boston, MA, USA

7 Cedars-Sinai Medical Center, Los Angeles, CA, USA

8 Department of Neurosurgery, San Raffaele University Health Institute Milan, Milan, Italy

9 Oxford Centre for Diabetes, Endocrinology and Metabolism, Churchill Hospital, Oxford, UK

10 Division of Endocrinology, San Raffaele University Hospital, Milan, Italy 